\title{
A teoria do dinheiro de Keynes: uma avaliação após 70 anos ${ }^{1}$
}

L. Randall Wray ${ }^{2}$

Resumo: Este trabalho examina duas visões de Keynes a respeito da moeda em sua Teoria Geral (GT). A primeira é a visão mais familiar de equilíbrio de "oferta e demanda" do Capítulo 13, incorporada à macroeconomia convencional tanto na versão ISLM quanto no monetarismo de Friedman. De fato, mesmo economistas pós-keynesianos que utilizam o "motivo financiamento" ou a curva de oferta "horizontal" de dinheiro acabam adotando uma metodologia similar. A segunda visão está no Capítulo 17 da GT, onde Keynes abandona a visão "oferta e demanda de moeda" em favor da visão de preferência por liquidez com relação aos preços dos ativos. Esta visão lida muito melhor com o papel fundamental exercido pela moeda em restringir a demanda efetiva numa economia capitalista. Volta-se, em uma seção do trabalho, a trabalhos anteriores de Keynes (o Tratado sobre a moeda e a rascunhos da GT) para se obter uma melhor compreensão sobre suas visões a respeito da natureza da moeda.

Palavras-chave: Keynes; economia keynesiana; moeda; preferência pela liquidez.

\section{Keynes's approach to money: an assessment after 70 years}

\footnotetext{
Abstract: This paper first examines two approaches to money adopted by Keynes in the General Theory (GT). The first is the more familiar "supply and demand" equilibrium approach of Chapter 13, incorporated within conventional macroeconomics in both the ISLM version as well as Friedman's monetarism. Indeed, even Post Keynesians utilizing Keynes's "finance motive" or the "hori-

1 Esta é uma versão mais extensa do artigo "Keynes's approach to money: an assessment after seventy years", publicado no Atlantic Economic Journal em junho de 2006. Tradução de Francisco Paulo Cipolla.

2 The Levy Economics Institute.
} 
zontal" money supply curve adopt similar methodology. The second approach of the GT is presented in Chapter 17, where Keynes drops "money supply and demand" in favor of a liquidity preference approach to asset prices. The Chapter 17 approach offers a much more satisfactory treatment of the fundamental role played by money to constrain effective demand in the capitalist economy. In the next section, I return to Keynes's earlier work, namely the Treatise on Money (TOM), as well as the early drafts of the GT, to obtain a better understanding of Keynes's views on the nature of money.

Key words: Keynes; Keynesian economics; money; liquidity preference.

JEL: E4; N1.

\section{A teoria da oferta e demanda de dinheiro de Keynes}

O capítulo 13 da Teoria Geral de Keynes procura responder a pergunta apresentada no primeiro parágrafo: o que determina a taxa de juros? Primeiramente, Keynes restringe o foco da análise definindo a taxa de juros como "a proporção inversa entre uma soma de dinheiro e o que se pode conseguir através da perda temporária de controle sobre essa soma de dinheiro em troca de uma dívida por um determinado período de tempo" (TG:167). A taxa de juros é, portanto, "o prêmio pela perda de liquidez" (TG), definição que nos leva inexoravelmente à conclusão de que a taxa de juros é “o 'preço' que equilibra o desejo de manter riqueza na forma dinheiro com a quantidade de dinheiro disponível" (TG). Esse desejo é chamado de "preferência pela liquidez" e, de acordo com Keynes, é "substancialmente a mesma coisa" que a "propensão a entesourar", desde que não seja confundido com "entesouramento" (TG: 174). Keynes alerta para o fato de que um aumento na preferência pela liquidez não pode fazer aumentar a quantidade de tesouro, "pois o volume de tesouro tem que ser igual à quantidade de dinheiro (...) e a quantidade de dinheiro não é determinada pelo público" (TG).

Resta então desenvolver os determinantes da quantidade de dinheiro e da preferência pela liquidez. No que tange a esta última, Keynes apresenta as "três divisões da preferência pela liquidez", quais sejam, o "motivo transação", o "motivo precaução" e o "motivo especulação" (TG:170). Esses motivos são discutidos em maior detalhe no capítulo 15, no qual Keynes faz a distinção entre as "duas funções de liquidez L1 e L2", a primeira "basicamente dependente do nível de renda enquanto a L2 depende principalmente da relação entre a taxa de juros corrente e o estado das expectativas" (TG:199). Essa se tornou, então, a versão padrão da demanda de dinheiro. Os pós-keynesianos, por outro lado, puseram mais ênfase na conexão feita por Keynes entre a função L2 e a incerteza, rejeitando a identificação ortodoxa da incerteza com o risco (Chick 1983; Tobin 1958). Nas palavras de Keynes: "vimos no capítulo 13 que a incerteza em relação ao futuro da taxa de juros é a única expli- 
cação plausível para o tipo de preferência pela liquidez L2 que leva à retenção de dinheiro M2" (TG:201). Ademais, Keynes teve cuidado em distinguir entre probabilidade e incerteza, principalmente por ocasião de sua defesa da Teoria Geral em 1937: "Por conhecimento 'incerto' não pretendo apenas distinguir o que se sabe com certeza daquilo que é somente provável" (CW 14:113) - i.e., o risco que pode ser coberto pelo seguro. Além dessa ressalva, muito pouco há nas explicações de Keynes nos capítulos 13 e 15 que permitam distinguir sua visão das apresentações convencionais de demanda de dinheiro tal como aparecem nos livros-texto do pós-guerra.

E quanto à oferta monetária? Apesar da interpretação usual de que na TG a determinação da taxa de juros pressupõe uma quantidade de dinheiro dada, a visão de Keynes em relação a esse ponto é menos clara. De fato, existem afirmações no sentido de que a oferta monetária é determinada pela política econômica, como por exemplo: "a quantidade de dinheiro tal como determinada pelas ações do Banco Central" (TG: 247); "a quantidade de dinheiro criada pela autoridade monetária" (TG: 205). Argumentos parecidos podem ser encontrados ao longo de toda a TG (:84, 167, 174, 230 e 267). Por outro lado, numa das poucas discussões detalhadas sobre o "modo como ocorrem as variações na oferta monetária”, Keynes discute três possibilidades.

Suponhamos que M seja constituído de moeda metálica e que mudanças na oferta monetária possam advir somente de retornos crescentes das atividades dos mineradores de ouro (...) O mesmo ocorre se as variações em $\mathrm{M}$ se devem à emissão de dinheiro por parte do Governo com o fim de suprir seus gastos correntes; nesse caso também o novo dinheiro se transforma em renda dos indivíduos (TG:200).

Ambos os casos podem ser reconciliados com dinheiro "exógeno".

Keynes, no entanto, discute o terceiro caso, no qual o dinheiro é criado pelos bancos e "onde dinheiro novo só pode ser emitido através de um afrouxamento das condições de crédito pelo sistema bancário com o intuito de induzir os agentes a vender dívidas para o banco ou títulos em troca de dinheiro novo" (TG). Ademais, em outros escritos Keynes levou em conta a possibilidade de variações "endógenas" na oferta monetária. No Tratado sobre a Reforma Monetária, por exemplo, ele argumenta que "o volume de dinheiro papel [notas bancárias](...) seria uma conseqüência, como de fato é no presente, do estado de comércio e emprego, da política de taxa de juros dos bancos e da política relativa às Letras do Tesouro (TMa:153). No TMa, Keynes reconhece que os próprios bancos "podem comprar ativos, ou seja, aumentar seus investimentos, e pagar por eles na forma de um crédito contra eles mesmos" 
(TMa:21). E afirma que "é evidente que não há limite para o volume de dinheiro que os bancos podem criar com segurança desde que todos eles avancem juntos" de modo a permitir que os ganhos e perdas de compensação se equilibrem (TMa:23). Por fim, em sua defesa da TG, ele diz: "minha análise não se baseia (...) na hipótese de que a quantidade de dinheiro é constante" (CW 14:232).

Essa visão parece refutar a curva de oferta monetária vertical apresentada nos livros-texto e ao mesmo tempo deixar em suspenso a determinação da taxa de juros devido à inter-relação entre as curvas de oferta e demanda de dinheiro. Keynes rejeita a interpretação de "oferta e demanda" quando diz que "a taxa de juros de curto prazo é facilmente controlada pela autoridade monetária porque não é difícil fazer crer que sua política não mudará muito no futuro próximo, como também porque a possível perda é pequena em comparação com os rendimentos correntes (...)" (TG:203). Keynes observa que é mais difícil para os bancos centrais determinar a estrutura a termo das taxas de juros e que essa capacidade "varia de acordo com os diferentes sistemas" (TG:206). Naquela que talvez possa ser considerada a sua mais completa exposição, Keynes diz:

O complexo de taxas de juros seria simplesmente a expressão das condições nas quais o sistema bancário está apto a adquirir ou liquidar dívidas; e a quantidade de dinheiro seria o montante possuído pelos indivíduos que - depois de levar em conta as circunstâncias relevantes - preferem o controle sobre dinheiro líquido ao invés de separar-se dele por uma dívida nas condições indicadas pela taxa de juros de mercado (TG:205-6).

Nesse contexto, a política do banco central não opera através do controle da oferta de dinheiro, mas sim através do seu impacto sobre as expectativas a respeito da taxa de juros e sobre a "disposição" dos bancos em "adquirir" dívidas. Se assim é, então é inadequada a apresentação tradicional da curva de oferta vertical e da curva de demanda negativamente inclinada. Keynes também defende a idéia de que "a taxa de juros é altamente convencional" e argumenta que "qualquer nível de juros aceito como duradouro será duradouro (...)" (TG:203), visão essa que rompe a metodologia de equilíbrio daqueles capítulos.

\section{Capítulo 17 e a abordagem do preço dos ativos pela preferência pela liquidez}

O desemprego é normalmente explicado por fricções de curto prazo ou desvios temporários do equilíbrio causados por "choques" ou "surpre- 
sas”. Kregel (1976), no entanto, argumenta que Keynes rejeitava as interpretações baseadas na frustração das expectativas ou na diferença entre expectativas ex ante e os resultados ex post, como causa do equilíbrio de desemprego. Ao contrário, Keynes assumia "que as expectativas de longo prazo são constantes e que as expectativas de curto prazo são sempre satisfeitas para deixar as expectativas num segundo plano e dar toda ênfase à demanda efetiva. Keynes preferiu esse modelo estático, sem frustração ou mudança de expectativa para demonstrar que o desemprego não era um fenômeno de desequilíbrio de curto prazo (...)" (Kregel 1976:213). Esse modelo estático adota três possíveis diferentes metodologias usadas por Keynes na TG. A segunda metodologia, a do equilíbrio estacionário, introduz a possibilidade de frustração das expectativas de curto prazo que não afetem as expectativas de longo prazo. No modelo dinâmico completo de deslocamentos de equilíbrio, as "frustrações correntes podem afetar o estado geral das expectativas" (Kregel 1976:215). Esses modelos mais complicados são necessários para a análise de como os empresários reagem às diferenças entre expectativas ex ante e resultados ex post. Keynes, porém, não necessitava basear-se neles para explicar o desemprego. Se a existência do desemprego pode ser demonstrada pelo modelo mais simples, é claro que o desemprego existirá também nos modelos nos quais as expectativas podem não se cumprir.

No Capítulo 17, Keynes generaliza a definição de taxa de juros como sendo, por exemplo, uma certa quantidade de trigo a ser entregue daqui a um ano cujo valor de troca hoje é igual a 100 quarters de trigo para entrega imediata (TG:222). “Assim, para qualquer mercadoria durável temos uma taxa de juros em termos dela mesma - uma taxa de juros do cobre, uma taxa de juros da casa e até mesmo a taxa de juros de uma fábrica de aço" (TG:222-3). Cada umas dessas taxas próprias de juros podem ser expressas em termos de dinheiro, o qual possui a mais alta taxa de juros em termos de si próprio e, portanto, "governa o galinheiro”, já que o dinheiro tem propriedades especiais e peculiares (TG:223; ver também Kregel 1997).

O retorno esperado de qualquer ativo medido em termos monetários é $q-c+l+a$, onde $q$ é o ganho que se espera daquele ativo, $c$ representa os custos de manutenção (carrying costs), $l$ é a liquidez e $a$ é a valorização esperada do preço do ativo. Esse retorno total pode ser usado para calcular a eficiência marginal de qualquer ativo, inclusive o dinheiro. A composição dos retornos varia de ativo para ativo, sendo que os ativos não líquidos têm a maior parte do retorno em termos de $q$-c, enquanto a maior parte do retorno dos ativos líquidos consiste de $l$, avaliado subjetivamente. Se um ativo reproduzível apresenta uma eficiência marginal maior do que o dinheiro, ele é produzido até o ponto em que sua eficiência marginal se equipara com a eficiência marginal do dinheiro, 
ativo que "governa o galinheiro". Um ativo não reproduzível que tenha uma eficiência marginal maior do que o dinheiro terá seu preço aumentado até o ponto em que seu retorno se iguale ao retorno do dinheiro. Por fim, mudanças nas expectativas têm impactos diferentes sobre a eficiência marginal dos diferentes tipos de ativos. O aumento da confiança sobre a performance futura da economia leva a um aumento dos $q s$ dos ativos de capital e diminui os valores subjetivos atribuídos às posições de liquidez (os $l s$ caem), de modo que a eficiência marginal do capital aumenta relativamente aos ativos que obtêm a maior parte do seu retorno a partir de $l$. Nesse caso, ativos de capital serão produzidos (investimento aumenta, acionando o "multiplicador") e todo o espectro de preços dos ativos muda. Portanto, as expectativas relativas ao futuro entram na determinação do nível de equilíbrio do produto e do emprego, nível esse definido como a posição na qual as firmas contratam exatamente aquela quantidade de trabalho para produzir o montante de produto que esperam vender.

No Capítulo 17, mais do que servir de base para a demanda especulativa de dinheiro, as expectativas têm um papel na determinação das taxas próprias de juros. Existe uma taxa própria para qualquer coisa que possa ser objeto de posse, taxa essa que é uma função dos ganhos esperados, dos custos de manutenção, dos retornos subjetivos relativos à liquidez e da valorização esperada dos preços. O retorno do "dinheiro" é subjetivamente determinado pelo valor atribuído a uma posição de liquidez; é necessário um prêmio para induzir o indivíduo a abandonar uma posição líquida. Como Keynes disse em 1937: "A posse do dinheiro acalma nossa inquietação e o prêmio que requeremos para renunciar à posse do dinheiro é uma medida do nosso grau de inquietação" (CW 14: 116). Mas essa "inquietação" afeta a demanda de todo o espectro de ativos, claro, de modo diferenciado, de acordo com a composição dos retornos esperados de cada ativo. O equilíbrio de preços dos ativos se dá quando as eficiências marginais são igualadas - e não simplesmente quando oferta e demanda de dinheiro se igualam. Por fim, mudanças no grau de "inquietação" têm um impacto direto sobre o emprego através de sua influência sobre as eficiências marginais.

Keynes enfatiza que "não há um padrão de 'liquidez' mas tão-somente uma escala de liquidez". De fato, diz ele, "a concepção do que contribui para a 'liquidez' é algo relativamente vago, mudando ao longo do tempo de acordo com as instituições e práticas sociais" (TG:240). À primeira vista, pareceria que um aumento da "liquidez' reduziria o valor atribuído a $l$, fazendo assim aumentar relativamente as eficiências marginais dos ativos não líquidos e levando a um aumento do emprego. Porém, as coisas talvez não sejam tão simples. Keynes argumenta que uma das peculiaridades do dinheiro é a sua pequena "elasticidade de produção". Isso significa que "a resposta da quantidade de trabalho utilizada para 
produzi-lo, em relação à quantidade de trabalho que uma unidade de dinheiro comanda" é minúscula (TG:230). Isso não significa, porém, uma quantidade fixa de dinheiro face à crescente demanda, mas tãosomente que o aumento da preferência pela liquidez não é capaz de manter o trabalho empregado na produção de dinheiro. Essa é a razão pela qual Keynes diz que o "desemprego aparece porque as pessoas desejam a lua; as pessoas não podem conseguir emprego quando o objeto do desejo (i.e. o dinheiro) é algo que não pode ser produzido e cuja demanda não pode ser imediatamente satisfeita" (TG:235).

Keynes argumentou (até mesmo no modelo de equilíbrio estático, sem frustração de expectativas) que a existência do dinheiro é a causa do desemprego porque "na ausência do dinheiro (...) o equilíbrio entre as taxas de juros ocorreria somente no pleno emprego" (TG:235). Keynes se refere, aqui, ao espectro de taxas próprias de juros, taxas essas que numa economia não monetária só se equiparam no pleno emprego. No entanto, o dinheiro (ou qualquer outra mercadoria com propriedades similares) estabelece um padrão que é muito alto para o pleno emprego. Keynes ainda alerta para o fato de que um "aumento da oferta de dinheiro" não é necessariamente a solução, pois "podem existir vários escorregões entre a taça e os lábios" (TG:173). Se a preferência pela liquidez crescer mais rapidamente (ou se a eficiência marginal dos ativos reproduzíveis estiver caindo mais rapidamente) que a oferta de dinheiro, então, não será possível estimular o emprego. A análise do impacto da política monetária sobre o emprego obriga Keynes a ultrapassar o marco do equilíbrio estático para analisar o impacto da política monetária sobre as expectativas de curto e longo prazo - o que ele faz em vários trechos da TG, concluindo que os efeitos são imprevisíveis e podem até ser contraproducentes. Keynes se mostra um "pouco cético em relação à possibilidade de sucesso da mera política monetária direcionada a influenciar a taxa de juros (...) já que é provável que variações na estimativa da eficiência marginal dos diferentes tipos de capital (...) sejam muito grandes para serem compensadas por mudanças factíveis na taxa de juros" (TG:164). Essa é a razão pela qual Keynes dá mais ênfase à eficácia da política fiscal, especialmente no Capítulo 24.

\section{O motivo financiamento: pedra fundamental ou desvio?}

Em sua defesa da TG, Keynes propôs uma quarta razão para a demanda de dinheiro: o motivo financiamento. Esse adendo tinha dois objetivos. $\mathrm{O}$ primeiro foi o de dar um papel proeminente para as expectativas na demanda por dinheiro L1. O segundo foi o de mostrar que o aumento da escala de produção não necessariamente deveria pressionar as taxas de juros. O primeiro ponto constitui uma resposta às críticas de Ohlin e 
Robertson, enquanto o segundo serviu de crítica à exposição de Hicks, que se tornou conhecida como a análise ISLM. O motivo financiamento de Keynes foi tomado como uma extensão da análise dos Capítulos 13 e 15 e foi também usado por alguns pós-keynesianos para resolver a aparente contradição de Keynes a respeito dos determinantes da quantidade de dinheiro. O meu argumento é que isso é basicamente um desvio.

Na sua réplica de dezembro de 1937, Keynes sugere um quarto motivo para a demanda de dinheiro, sendo ele uma função dos gastos esperados:

Eu não deveria ter deixado esse ponto ter passado desapercebido, já que ele é a pedra fundamental da teoria da preferência pela liquidez da taxa de juros. Como sempre argumentei, um aumento do nível de atividade deve levar a um aumento da taxa de juros, a não ser que os bancos ou as pessoas aumentem a predisposição a fornecer dinheiro; a mesma influência, adiciono agora, deve resultar de um aumento do nível de atividade planejado (CW14:220-221).

A ressalva de que o aumento da demanda de dinheiro não deve necessariamente causar uma elevação da taxa de juros, desde que os bancos ou outros agentes estejam dispostos a aceitar essa demanda, foi enfatizada por Keynes em sua carta de 31 de março a Hicks: "É importante enfatizar que a minha afirmação significa que um aumento da indução a investir não deve necessariamente causar um aumento da taxa de juros. Porém, se a política monetária não for apropriada, é muito provável que aquele aumento aconteça" (CW14:80). Assim, um aumento dos gastos planejados - como também dos gastos de fato - aumenta a demanda de dinheiro, o que eleva a taxa de juros, a não ser que a oferta monetária cresça na mesma proporção.

Após a TG, Keynes desenvolveu várias análises do processo de financiamento, nas quais expôs suas objeções à abordagem dos fundos de empréstimo e às tentativas de Robertson de juntar poupança e empréstimos bancários como fonte híbrida de financiamento. $\mathrm{O}$ argumento de Keynes era de que poupança e financiamento não são a mesma coisa: "A poupança não tem a mesma eficácia que o consumo em fazer fluir o dinheiro e restaurar a liquidez (...) Há tanta razão para adicionar os gastos de consumo à taxa de aumento do dinheiro bancário para a determinação do fluxo de dinheiro que se torna disponível para o novo 'financiamento' quanto de se adicionar a poupança corrente" (CW 14:233). Demanda e oferta de "fundos de empréstimo" são necessariamente iguais, não havendo, portanto, nenhuma necessidade de ajustamento na taxa de juros: "O aumento do investimento será sempre acompanhado de um aumento na poupança, mas jamais pode ser precedido pela poupança. Desentesouramento e expansão do crédito não consti- 
tuem uma alternativa ao aumento da poupança, mas uma preparação necessária para o seu aumento; é o pai e não o irmão gêmeo do aumento da poupança” (CW14:281).

O investimento por si só não pode pressionar as taxas de juros porque ele retorna ao "fundo rotativo de financiamento", criando uma poupança equivalente (CW14:208). Se por um lado o investimento não pode ser inibido por falta de poupança, ele pode sê-lo por falta de financiamento no período de tempo em que o dinheiro é entesourado pelo motivo financiamento: "a não ser que o sistema bancário esteja preparado para aumentar a oferta de dinheiro, a falta de financiamento pode se tornar um obstáculo para que mais decisões de investimento não sejam contempladas ao mesmo tempo. Mas financiamento nada tem a ver com poupança" (CW14:247). Se os bancos suprem o crédito para satisfazer a demanda por financiamento, as taxas de juros não aumentarão com o aumento do nível de atividade. Por fim, Keynes observa que "na medida em que o sistema de overdraft é empregado e overdrafts não utilizados são ignorados pelo sistema bancário, não há nenhuma pressão resultante da atividade planejada acima da pressão resultante da atividade corrente" (CW14:222-3).

Essa visão constitui uma crítica contumaz das abordagens da taxa de juros baseadas na ISLM ou na teoria dos fundos de empréstimo. Davidson (1965) argumenta que a interdependência entre demanda de dinheiro e gastos planejados tem a implicação de que não se pode separar os setores real e monetário. Por isso o dinheiro não pode ser neutro. Contudo, se a "oferta de dinheiro" responde à "demanda por dinheiro", as duas funções não podem ser independentes e Keynes fica sem uma explicação convincente para a determinação da taxa de juros nos termos do Capítulo 13.

De fato, vários autores pós-keynesianos argumentam que a teoria de Keynes é fundamentalmente falha precisamente por essa razão. Ademais, procuraram uma alternativa no debate ao redor do motivo financiamento. O motivo financiamento é interpretado como demanda de dinheiro em função do fluxo de gastos planejados - não como desejo de reter dinheiro, mas, ao contrário, como desejo de gastar. Se adicionarmos a afirmação de Keynes sobre overdrafts, se presume que a "oferta de dinheiro" se adapta à "demanda de dinheiro", fazendo com que o aumento dos gastos não tenha nenhum impacto sobre a taxa de juros. Moore (1988) propôs uma curva de oferta de dinheiro horizontal a uma taxa de juros que é um markup sobre a taxa de juros alvo administrada pelo banco central. A oferta de dinheiro é endógena, enquanto a taxa de juros é exógena. Assim, não só a ISLM é derrotada, como também não há nenhum papel para a preferência pela liquidez tida como dependente de uma oferta monetária fixa ou - ainda pior - para uma teoria dos fundos de empréstimo (Lavoie 1985). 
Esses argumentos, no entanto, se chocam frontalmente com a abordagem de Keynes no Capítulo 17. Tenhamos em mente o modelo de equilíbrio estático. Quando alguém toma uma decisão de investir, a eficiência marginal do ativo é comparada com a eficiência marginal do dinheiro. $\mathrm{O}$ possível efeito da elevação do nível de atividade sobre a taxa de juros não é conhecido nem levado em consideração (por hipótese) pelo indivíduo no momento em que toma a decisão ex ante de investir. Ele levará em consideração os custos financeiros (que podem ser crescentes à medida que se aumenta o financiamento externo, como na teoria de Minsky), mas não seria legítimo supor que ele leva em consideração o efeito da elevação do nível de atividade sobre a taxa de juros ao tomar sua decisão.

Da mesma forma, as forças que igualam as eficiências marginais não dependem de qualquer função de oferta de dinheiro - tudo o que importa é o modo como os termos de financiamento afetam a eficiência marginal do capital no momento em que as decisões de investimento são realizadas. Na discussão de dinâmica, temos que abandonar o método do equilíbrio estático de modo que "a observação do erro altera o estado de expectativas e desloca as funções de comportamento" e, assim, "o modelo de deslocamento de equilíbrio de Keynes descreve a trajetória real de uma economia perseguindo um equilíbrio que muda continuamente sem que necessite jamais alcançá-lo" (Kregel 1976:217). O método de equilíbrio estático, em contraste, permite a Keynes uma simplificação suficiente para enfatizar o papel da preferência pela liquidez na determinação do nível de equilíbrio da demanda efetiva, equilíbrio esse não necessariamente de pleno emprego. Aqui o caráter endógeno ou exógeno da oferta monetária não é relevante. O motivo financiamento também não é relevante, nem a maneira como é financiado o aumento do nível de atividade; é suficiente que o dinheiro tenha "características peculiares" que façam com que sua eficiência marginal "governe o galinheiro".

Não queremos com isso negar a importância de incorporar o dinheiro endógeno à teoria de Keynes. De fato, até a economia ortodoxa rejeita o controle da oferta monetária pelo banco central, sendo que algumas abordagens assumem explicitamente que a oferta monetária - em sentido amplo - se expande à medida que os gastos crescem, o que implicitamente significa uma rejeição da abordagem de oferta e demanda da taxa de juros. No entanto, essa rejeição não significa que a preferência pela liquidez de Keynes - tal como apresentada no Capítulo 17 - deva ser descartada. Da mesma forma, a frustração das expectativas é importante para a análise de movimento da economia no tempo na medida em que causa o deslocamento do equilíbrio. No entanto, o desemprego seria possível mesmo se as expectativas de curto e longo prazos se verificassem - bastando para isso que a preferência pela liquidez tenha in- 
fluência na determinação do preço dos ativos e que a composição dos retornos esperados varie de ativo para ativo, sendo que alguns deles tenham a maior parte de seus retornos em termos de liquidez.

Como reconciliar a preferência pela liquidez de Keynes com o fato dos bancos centrais trabalharem com uma taxa de juros alvo de curto prazo? Primeiramente, é preciso admitir que mesmo admitindo que os bancos centrais tenham um controle substancial sobre a taxa de juros de curto prazo, Keynes não deixou de promover a abordagem da preferência pela liquidez. Ademais, mesmo se aceitássemos um controle discricionário completo sobre a taxa de juros overnight e uma influência substancial sobre as taxas de juro de longo prazo, como no caso dos títulos de dívida do governo, mesmo assim a preferência pela liquidez continuaria tendo um papel na determinação de todas as outras taxas próprias de juros. Keynes nunca advogou em favor de uma causa única. Ao contrário, escolheu o papel desempenhado pela preferência pela liquidez por acreditar que constituía a barreira principal a impedir o funcionamento da economia ao nível de pleno emprego. Na sua visão, nem mesmo uma política econômica esclarecida seria capaz de ajustar as eficiências marginais de modo a produzir o pleno emprego. O dinheiro pode ser criado. Porém, se as eficiências marginais dos bens produzíveis forem muito baixas, trabalho não será empregado.

Em trabalho anterior (Wray 1990), apresentei a diferença entre preferência pela liquidez (desejo de manter ativos líquidos) e a demanda de dinheiro (concebida como demanda de novos empréstimos). O aumento da demanda de dinheiro leva normalmente a um aumento da oferta de dinheiro (definida como um aumento dos passivos bancários à medida que os bancos fazem os empréstimos) pelas instituições financeiras. O que ocorrerá com a taxa de juros depende de inúmeros fatores, entre eles a política econômica esperada e a preferência pela liquidez dos bancos, mas de qualquer modo uma oferta de empréstimos completamente elástica é improvável. Por outro lado, o aumento da preferência pela liquidez está associado a uma redução dos gastos planejados na medida em que as eficiências marginais dos ativos reproduzíveis caem relativamente à rentabilidade dos ativos líquidos. É por essa razão que a demanda de dinheiro (tal como definida acima) pode cair quando a preferência pela liquidez, aumenta. Desse modo, a oferta de dinheiro normalmente não acompanhará o aumento da preferência pela liquidez; ao contrário, é o preço dos ativos que se ajusta até o ponto no qual os detentores desses ativos ficam satisfeitos em mantê-los em sua posse. Assim, dinheiro endógeno pode ser reconciliado com a preferência pela liquidez, tornando claro que o motivo financiamento não é o desejo de manter a riqueza na forma de dinheiro, mas sim um fluxo de demanda por financiamento. Devemos, portanto, manter o motivo financiamento separado dos outros três motivos. 


\title{
A natureza do dinheiro
}

Se o dinheiro é a causa última do desemprego, por que então as economias se estruturam com base nele? A visão ortodoxa de que o dinheiro foi adotado para reduzir custos de transação conflita com a visão de Keynes de que o dinheiro impede a economia de funcionar a pleno uso da capacidade. Keynes acreditava que o dinheiro tinha uma função mais fundamental do que a de "lubrificante" do mecanismo de mercado. Na TG, Keynes explicitamente propôs "a teoria da economia monetária" que é "um sistema no qual mudanças na visão a respeito do futuro são capazes de mudar o presente" (TG:293). Na preparação da TG, Keynes mencionou "a teoria monetária da produção", que trataria

\begin{abstract}
de uma economia na qual o dinheiro tem uma função própria, afeta as motivações e decisões e é, em suma, um dos fatores fundamentais, de modo que não se pode prever o desenrolar dos eventos, seja no longo seja no curto prazo, sem que se saiba qual será o comportamento do dinheiro entre o momento inicial e o momento final. E é isso que queremos dizer quando falamos de economia monetária (CW13:408-409).
\end{abstract}

Keynes diferencia essa economia de uma "economia de trocas reais", que pode usar o dinheiro mas "não permite que ele afete as motivações e decisões (CW13).

Muitos atribuem a preocupação de Keynes a respeito do dinheiro à incerteza em relação ao futuro. Como disse ele, "parte racionalmente, parte instintivamente, nosso desejo de manter dinheiro como reserva de riqueza é uma medida do grau de dúvida em relação aos nossos próprios cálculos e convenções a respeito do futuro" (CW14:116-117). Alguns pós-keynesianos argumentam que a existência da incerteza leva ao uso de contratos monetários e, de fato, argumentam que o dinheiro existe porque o futuro é incerto. De acordo com Davidson, os Keynesianos reconhecem "a existência de instituições de mercado específicas, organizações e restrições (como, por exemplo, contratos monetários, sistema legal, dinheiro e salários monetários rígidos) que só existem devido à incerteza presente" (Davidson 1974:91). Dow argumenta que "o fato de que quase todas as sociedades empreguem alguma forma de dinheiro representa uma resposta à incerteza" (Dow 1993:19). Ademais, "as incertezas associadas às ações relativas a um futuro desconhecido (ações essas que não podem ser desfeitas) levaram ao amplo uso de contratos monetários (...)”. (Dow 1993:20). Tudo isso, porém, pode virar exagero se for interpretado no sentido de que o dinheiro existe devido à incerteza. Keynes toma o dinheiro como dado quando argumenta que ninguém reteria dinheiro como reserva de riqueza na ausência de incerteza - na verdade ninguém "fora do asilo de loucos" 
reteria riqueza na forma de dinheiro num mundo neoclássico ( $\mathrm{CW}$ 14: 116). Mas isso não significa que o uso de dinheiro requer a incerteza e tampouco que a origem do dinheiro ou mesmo o segredo de sua natureza está na incerteza.

No TM, Keynes defendeu a idéia de que "o dinheiro de conta aparece junto com dívidas - que são contratos de pagamento diferidos - e listas de preços - que são ofertas de contratos de compra ou venda (...) e que podem ser expressos somente em termos de dinheiro de conta" (TMa: 3). Keynes diferenciou entre "dinheiro e dinheiro de conta ao dizer que dinheiro de conta é a descrição ou título e o dinheiro é a coisa que responde àquela descrição" (TMa). E ainda mais, o estado

reivindica o direito de determinar que coisa corresponderá ao nome e de variar essa determinação ocasionalmente como se reivindicasse o direito de reeditar o dicionário. Esse direito é reivindicado por todos os Estados modernos e assim tem sido pelo menos nos últimos quatro mil anos. É quando atingimos esse estado na evolução do dinheiro que o cartalismo de Knapp - a doutrina de que o dinheiro é uma criação do Estado - se realiza plenamente (TMa:4).

Finalmente, "a era do cartalismo ou dinheiro de Estado é alcançada quando o Estado reivindica o direito de declarar que coisa corresponde ao dinheiro de conta - isto é, quando ele reivindica não só o direito de impor o dicionário, mas também o direito de reescrevê-lo. Hoje em dia, sem qualquer sombra de dúvida, todo o dinheiro civilizado é cartalista" (TMa).

Essas idéias têm raízes que remontam ao trabalho não publicado de Keynes sobre o dinheiro antigo, assim como à sua resenha de 1914 do artigo de A. Mitchell Innes. Como afirmava Keynes, "desde os seus primórdios até a introdução do sistema monetário, o padrão fundamental de peso da civilização ocidental jamais foi alterado" (CW28:239). Esse padrão serviu de base para as unidades monetárias, sejam elas a livre, mina, shekel ou libra (CW 28; Innes 1913:386; Wray 1998:48). Hudson explica que as unidades monetárias desenvolvidas nos templos e palácios de Sumer no terceiro milênio a.C. foram criadas por motivos administrativos internos: "as instituições públicas estabeleceram um ponto de referência monetário ao fazer o peso-shekel de prata (240 grãos de cevada) ter o mesmo valor que a unidade de consumo mensal, um "bushel" de cevada, a mercadoria mais importante do comércio" (Hudson 2004:111). Assim, ao invés do valor intrínseco do metal (ou mesmo o valor de troca) dar origem ao numerário, as autoridades definiram o valor monetário do metal como sendo igual ao numerário derivado do peso da unidade de consumo mensal de grãos. Nesse veio, Keynes deu apoio à rejeição da história da evolução do dinheiro mercadoria a 
dinheiro de crédito e fiat money. O valor das moedas nunca foi determinado pelo metal incorporado nelas; ao contrário, elas sempre "foram moedas simbólicas, cujo valor de troca enquanto dinheiro difere em graus variados do seu valor intrínseco" (Keynes 1914:420).

Assim como Knapp, Innes argumenta que o estado "impõe o dicionário" através da imposição de um passivo tributário sobre o dinheiro de conta. O estado garante a aceitabilidade geral do dinheiro que ele emite ao aceitar recebê-lo como pagamento pelos impostos. Condição suficiente para que o dinheiro de estado seja aceito é, portanto, que os impostos sejam de fato obrigatórios. Como diz Innes:

\begin{abstract}
Por lei o governo obriga certas pessoas a se transformarem em seus devedores. Declara, por exemplo, que aquele que importa bens do exterior deverá ao governo uma certa proporção do valor de suas importações ou que, por exemplo, aquele que possuir terras deverá ao governo uma certa quantia por acre possuído. Esse procedimento de imposição de impostos faz com que os indivíduos forçados à posição de devedores de impostos tenham que procurar indivíduos que tenham instrumentos de dívida do governo para adquiri-los através da venda de uma mercadoria ou serviço em troca do qual esses indivíduos possam renunciar aos títulos de dívida do governo. Quando retornam ao Tesouro, os impostos estão pagos (Innes 2004:398).
\end{abstract}

O estado também pode aprovar leis monetárias ou proceder à regulação de reservas bancárias, mas isso não é necessário nem suficiente para que o dinheiro estatal seja aceito. Na sua resenha, Keynes concluiu: "O desenvolvimento da tese do Sr. Innes é de inquestionável interesse (...) As principais conclusões históricas que ele apresenta têm, na minha opinião, fundamento (...)” (Keynes 1914:421).

No TM, Keynes explica que o dinheiro é uma "categoria derivada" a partir do dinheiro de conta. Os dois tipos de derivações são "ofertas de contratos, contratos e títulos de dívidas que são realizados em termos de dinheiro de conta e dinheiro propriamente dito, capaz de responder ao contrato e cuja entrega desfaz o contrato ou dívida" (TMa:5). Os indivíduos descobrem "que em muitas ocasiões títulos de dívida funcionam como substituto para o dinheiro na liquidação de transações" (TMa). Nas economias modernas, o dinheiro bancário é o mais importante. "Temos então, lado a lado, dinheiro Estatal, ou dinheiro propriamente dito, e dinheiro bancário ou títulos de dívida" (TMa). O estado pode utilizar suas prerrogativas cartalistas e declarar que o débito bancário pode ser utilizado para cancelar um passivo" (TMa). Dinheiro bancário se transforma em dinheiro propriamente dito mudando "seu caráter", de modo que "ele não deve mais ser reconhecido como dívida, já que é 
da essência de uma dívida que ela seja exigível em termos de algo diferente dela mesma" (TMa).

Innes insistia que mesmo o dinheiro propriamente dito era uma dívida, ainda que de tipo peculiar. Se por um lado é verdade que o fiat money não pode ser exigido em termos de nenhuma outra coisa, por outro ele compartilha com todas as outras formas de dívida a promessa de que deve ser aceito por quem o emitiu. De acordo com Innes, essa é "a natureza mesma do crédito em todo o mundo", que é "o direito daquele que detém o crédito (o credor) de devolver àquele que emitiu a dívida (o devedor) o título ou obrigação deste último" (Innes 1914:161). Dinheiro estatal - como qualquer passivo - tem que refluir de volta àquele que o emitiu.

O detentor de uma moeda ou certificado tem o direito absoluto de pagar qualquer dívida para com o governo entregando a ele aquela moeda ou certificado e é esse direito e nada mais que dá a eles o seu valor. É irrelevante se o direito emana da legislação ou mesmo se existe uma legislação que defina a natureza da moeda ou certificado (Innes 1914: 161).

Mesmo assim, o dinheiro estatal é diferente porque é "resgatável pelo mecanismo da tributação" (Innes 1914:15): "É o imposto que dá ao dinheiro o seu 'valor' (...). Uma nota de um dólar é um dólar não devido ao material do qual é feito, mas devido ao dólar de imposto necessário para resgatá-lo" (Innes 1914:152). Em outras palavras, o que está na base do dinheiro estatal é a obrigação do estado de aceitá-lo como meio de pagamento dos impostos. Podemos denominar isso de poder soberano - o poder de impor tributos e de emitir o meio através do qual o pagamento dos tributos é aceito.

Quando um banco faz um empréstimo, ele aceita uma dívida e emite sua própria dívida; o devedor do banco liquida sua dívida devolvendo a dívida bancária, coisa que o banco não pode recusar. Obviamente, todos os sistemas bancários modernos têm uma casa de compensação, de modo que o devedor do banco pode devolver o passivo de qualquer banco. Da mesma forma, tal como observado por Keynes, passivos tributários são liquidados na maioria dos casos pela entrega de passivos bancários, sendo que o banco central faz a compensação das contas dos bancos privados e do tesouro. Existe uma hierarquia de dinheiros na qual passivos bancários são utilizados pelo setor não governamental e passivos governamentais são usados para a compensação entre os bancos e com o governo. Dada essa organização, os bancos necessitam manter reservas para compensação (como nos EUA) ou devem ter acesso imediato a eles (como no Canadá, onde os bancos têm permissão de zerar suas reservas). Em última análise, o banco central não pode se 
recusar a disponibilizar reservas para compensação se pretende manter em ordem o sistema de pagamentos com passivos bancários circulando em pé de igualdade. Ademais, para atingir sua taxa de juros alvo, o banco central tem que atender a demanda de reservas.

\section{Keynes e o sistema monetário internacional}

Na opinião de Keynes, o dinheiro estatal pode assumir três formas: "Dinheiro mercadoria, fiat money e dinheiro administrado, sendo as últimas duas subespécies do Dinheiro Representativo" (TMa:7). O dinheiro mercadoria é definido como "unidades de qualquer mercadoria - não monopolizada e passível de ser livremente obtida - que tiver sido escolhida para fazer as funções do dinheiro" ou "direitos de depósito sobre quantidades de mercadorias realmente existentes" (TMa). Fiat money é dinheiro representativo "criado e emitido pelo estado, mas por lei não conversível em nada exceto nele mesmo e sem nenhum valor fixo em termos de qualquer padrão objetivo" (TMa:8). A forma mais generalizada de dinheiro, na opinião de Keynes, é o dinheiro administrado, que pode "degenerar, por um lado, em Dinheiro Mercadoria, quando a autoridade monetária determina sua convertibilidade em $100 \%$ do padrão objetivo, o que o torna na verdade um direito de depósito, e por outro, em Fiat Money, quando perde completamente o seu padrão objetivo" (TMa). Tanto o padrão ouro quanto o sistema de Bretton Woods, com taxas de câmbio fixas mas ajustáveis, eram sistemas de dinheiro administrado. A maioria dos países, hoje em dia, têm sistemas baseados no fiat money - o dólar dos EUA, o yen no Japão e assim por diante. Se por um lado o euro é fiat money na medida em que não é "conversível por lei em nada exceto nele mesmo", por outro, os membros da União Monetária Européia são utilizadores e não emissores do euro. Por isso, as nações européias se aproximam do extremo de "dinheiro mercadoria" no espectro do dinheiro administrado.

Keynes propôs uma alternativa ao sistema de Bretton Woods, na qual haveria taxas de câmbio fixas, mas ajustáveis, combinadas com um mecanismo de penalizar as nações com balanços comerciais deficitários ou superavitários com o fim de promover o "influxo" das reservas internacionais, - o seu plano "bancor". Isso reduziria a tendência a "empobrecer o vizinho" causada pelo acúmulo de reservas internacionais, cujo efeito sobre a demanda efetiva global é negativo. Depois da ruptura do sistema de Bretton Woods, alguns economistas ortodoxos acreditavam que as forças de mercado internacionais, num regime de taxas de câmbio flutuantes, tenderiam a gerar equilíbrio comercial; na verdade, não só o comércio se tornou mais desequilibrado, como também as crises cambiais internacionais se proliferaram. Alguns pós-keynesianos, as- 
sim como outros economistas, retornaram ao plano original de Keynes, propondo uma volta ao sistema de taxas de câmbio fixas. Parece, no entanto, haver muito pouca substância política para o nível de cooperação internacional necessária para reproduzir algo próximo do que foi o sistema de Bretton Woods. Ademais, a limitada experiência européia de abandono das moedas nacionais em favor do euro, assim como a adoção do regime de paridade cambial por muitos países em desenvolvimento - experiências que representam formas extremas de taxas de câmbio fixas - parecem questionar a inteligência dessa estratégia (Ver Goodhart 1998; Wray 1998). O abandono das moedas nacionais restringe demasiadamente tanto a política fiscal quanto a monetária, na medida em que o governo tenta formar reservas internacionais para proteger o câmbio e para "financiar" os gastos públicos. Não é por acaso que países que adotaram a paridade cambial ou que aderiram ao euro procuraram obter superávits comerciais e balanço nas contas do tesouro.

Haveria uma alternativa estratégica, keynesiana, para o século XXI? Na TG, Keynes conclui que "sob o sistema do liberalismo doméstico e padrão ouro internacional (...) não há como o governo mitigar as dificuldades econômicas domésticas, exceto através de uma luta competitiva por mercados" (TG:382). Sob esse sistema, "a Cidade de Londres foi aos poucos encontrando a técnica mais perigosa para a manutenção do equilíbrio que possa ser imaginada, qual seja, a técnica da taxa bancária [o ajuste da taxa de juros alvo para alcançar o desejado balanço comercial] junto com a rígida paridade cambial" (TG:339).

De alguma forma, podemos dizer que o mundo voltou para o ponto de partida da época de Keynes. Desemprego crônico para conter a demanda agregada é uma necessidade no contexto da luta competitiva por mercados externos. O mesmo se aplica a muitas nações da Ásia e América Latina, com seus experimentos de taxas de câmbio atreladas e políticas mercantilistas. Algumas nações ganharam nesse jogo, enquanto muitas outras sofreram taxas altas de desemprego, baixo crescimento e crises cambiais periódicas. A maioria dos países fora da Eurolândia operam com sistemas de fiat money e taxas de câmbio flexíveis, mas mesmo assim usam a política econômica para restringir a demanda efetiva no sentido de influenciar a taxa de câmbio e o balanço comercial.

No entanto, não precisamos fazer política econômica como se ainda estivéssemos no padrão ouro. Uma nação soberana que deixe sua moeda flutuar pode usar a política econômica para buscar o pleno emprego e o crescimento; pode estabelecer sua taxa de juros alvo sem se preocupar com o efeito da taxa de câmbio; pode, ademais, adotar uma política fiscal expansionista sem se preocupar com o efeito dos déficits comerciais sobre as taxas de câmbio ou sobre as reservas internacionais. Nesse caso, "o comércio internacional cessaria de ser um desesperado ex- 
pediente para manter o emprego doméstico à custa dos mercados externos (...) mas ao contrário, uma troca espontânea e livre de bens e serviços em condições de vantagem mútua" (TG:282-3). Com taxas de câmbio flutuantes e política econômica direcionada ao pleno emprego, as vantagens "reais e substanciais" do comércio podem, como dizia Keynes, ser usufruídas. Por outro lado, se a política econômica se orientar no sentido de deprimir a demanda para obter superávit comercial, então, não se poderão colher os benefícios do comércio.

Dada a dificuldade de se implantar, nas atuais circunstâncias políticas, a reforma do sistema monetário internacional tal como proposta por Keynes no plano bancor, moedas soberanas e taxas de câmbio flutuantes constituem a melhor forma de promover políticas fiscais e monetárias independentes.

\section{Conclusões}

A determinação da taxa de juros pela oferta e demanda de dinheiro apresentada por Keynes supriu uma alternativa à abordagem dos fundos de empréstimo e à teoria quantitativa da moeda como explicação do nível de preços. A adição do motivo financiamento, assim como a introdução de overdrafts e fundo rotativo de financiamento, somente serviram para enfatizar a fraqueza da abordagem de equilíbrio. O Capítulo 17 oferece um tratamento mais adequado para a determinação do preço dos ativos, indicando o papel peculiar representado pelo dinheiro no estabelecimento de um padrão de retorno que é, em geral, muito alto para permitir o nível de demanda efetiva de pleno emprego. Em trabalhos anteriores, Keynes havia fornecido observações importantes sobre a natureza do dinheiro e da economia monetária da produção. Em vez de dar importância ao papel do dinheiro como lubrificante da troca, Keynes enfatizou o papel de unidade de conta, assim como a função do estado de "escrever o dicionário". Ao impor passivos tributários na unidade de conta do estado, passivos esses a serem pagos no seu "dinheiro de fato", o estado estabelece não somente as condições para a criação privada de contratos monetários, mas também as condições para que os gastos do governo sirvam para aumentar a demanda efetiva. No entanto, no padrão ouro - ou em qualquer outro sistema de taxas de câmbio fixas sem mecanismo de refluxo internacional de reservas para países com conta corrente deficitária - a política de estabilização fica subordinada à luta competitiva por mercados externos. Um sistema de taxas de câmbio domésticas flexíveis libera a política doméstica para perseguir o pleno emprego. Porém, enquanto os agentes de política econômica continuarem a agir como "escravos de algum economista defunto", "algum escrevinhador acadêmico de alguns anos atrás" (TG: 
383), a demanda efetiva permanecerá cronicamente muito baixa para permitir que a economia opere ao seu nível "eficiente" de pleno emprego.

\section{Referências}

CHICK, Victoria (1983). Macroeconomics after Keynes: a reconsideration of the General Theory. Cambridge, MA: The MIT Press.

DAVIDSON, Paul (1974). “A Keynesian view of Friedman's theoretical framework for monetary analysis”. In GORDON R. (ed.). Milton Friedman's monetary framework. Chicago: The University of Chicago Press, pp. 90110 .

DAVIDSON, Paul (1965). "Keynes's finance motive”. Oxford Economic Papers $17(1): 47-65$.

DOW, Sheila C. (1993). Money and the economic process. Aldershot: Edward Elgar.

GARDINER, Geoffrey W. (2004). "The primacy of trade debts in the development of money". In WRAY, L.R. (ed.). Credit and state theories of money: the contributions of $A$. Mitchell Innes. Cheltenham: Edward Elgar, pp. 7998 .

GOODHART, Charles A. (1998). "Two concepts of money: implications for the analysis of optimal currency areas". European Journal of Political Economy 14:407-432.

HUDSON, Michael (2004). "The archaeology of money: debt versus barter theories of money's origins". In WRAY, L. R. (ed.). Credit and state theories of money: the contributions of A. Mitchell Innes. Cheltenham: Edward Elgar, pp. 99-127.

INNES, A. Mitchell (2004) [1913]. "What is money?” Banking Law Journal 30(5): 377-408. In WRAY, L.R. (ed.). Credit and state theories of money: the contributions of $A$. Mitchell Innes. Northampton: Edward Elgar, pp. 14-49.

INNES, A. Mitchell (2004) [1914]. "The credit theory of money". Banking Law Journal 31(2):151-68. In WRAY, L.R. (ed.). Credit and state theories of money: the contributions of A. Mitchell Innes. Northampton: Edward Elgar, pp. 50-78.

KEYNES, John M. (1914). "What is money?” Economic Journal 24(95): 41921.

(1964) The general theory of employment, interest, and money. Nova Iorque \& Londres: Harcourt Brace Jovanovich.

(1971) A tract on monetary reform. In MOGGRIDGE, D. E. (ed.). The collected writings of John Maynard Keynes vol. IV. Londres: Macmillan e Nova Iorque: Cambridge University Press for the Royal Economic Society.

(1971). A treatise on money, vol. 1 The pure theory of money. In MOGGRIDGE, D. E. (ed.). The collected writings of John Maynard Keynes, 
vol. V. Londres: Macmillan e Nova Iorque: Cambridge University Press for the Royal Economic Society.

KEYNES, John M. (1971). A treatise on money, vol. 2 The applied theory of money. In MOGGRIDGE, D. E. (ed.). The collected writings of John Maynard Keynes, vol. VI. Londres: Macmillan e Nova Iorque: Cambridge University Press for the Royal Economic Society.

(1973). The General Theory and after Part I Preparation. In MOGGRIDGE, D. E. (ed.). The collected writings of John Maynard Keynes, vol. XIII. Londres: Macmillan e Nova Iorque: Cambridge University Press for the Royal Economic Society.

(1973). The General Theory and after Part II. Defense and development. In MOGGRIDGE, D. E. (ed.). The collected writings of John Maynard Keynes. Vol. XIV. Londres: Macmillan; Nova Iorque: Cambridge University Press for the Royal Economic Society.

(1982). Social, political and literary writings. In MOGGRIDGE, D. E. (ed.). The collected writings of John Maynard Keynes. Vol. XXVIII. Londres: Macmillan; Nova Iorque: Cambridge University Press for the Royal Economic Society.

KREGEL, J. A. (1976). "Economic methodology in the face of uncertainty: the modeling methods of Keynes and the post Keynesians." The Economic Journal 86(342):209-25.

(1997). "The theory of value, expectations and chapter 17 of The General Theory." In HARCOURT, G. \& RIACH, P. (eds.). A 'Second Edition' of the General Theory. Vol. I. Londres \& Nova Iorque: Routledge, pp. 26182 .

LAVOIE, Marc (1985). "Credit and money: the dynamic circuit, overdraft economics, and post Keynesian economics." In MARC, Jarsulic (ed.). Money and macro policy. Boston: Dordrecht \& Lancaster.

MOORE, Basil (1988). Horizontalists and verticalists: the macroeconomics of credit money. Cambridge: Cambridge University Press.

TOBIN, James (1958). "Liquidity preference as behavior toward risk." Review of Economic Studies 25:65-86.

WRAY, L. Randall (1998). Understanding modern money: the key to full employment and price stability. Cheltenham, UK: Edward Elgar.

(1990). Money and credit in capitalist economies: the endogenous money approach. Aldershot, UK: Edward Elgar.

Artigo recebido em 30/05/2006. Aceite em 23/06/2006. 